\title{
Village differences in rural household energy consumption within the Loess hilly region of China
}

\author{
Guozhu Li , Jinxin Sun and Ailin Dai
}

\begin{abstract}
Background: There are obvious differences in rural household energy consumption, which vary according to the location of the households. At the village level, geographic factors significantly influence household energy choices and consumption. Therefore, it is vital to research differences in rural energy use among different types of villages to pertinently strengthen the implementation of rural energy policy and to correctly adjust the measures for local conditions.
\end{abstract}

Methods: For this study, typical villages were selected, and the related data were obtained by using questionnaire surveys and household interviews. We investigated the differences among villages regarding rural household energy consumption for mountainous, semi-mountainous, and plains areas in the Loess hilly region of Gansu Province.

Results: The results indicate obvious differences in rural household energy consumption among the different types of villages, although they shared the distinctive feature of utilizing a combination of energy sources; however, the level of rural household energy consumption is relatively low. In the mountainous areas, households mainly depend on straw and use coal, animal manure, solar energy, wood, and bio-gas as auxiliary energy sources. In the semi-mountainous areas, households mainly depend on coal and use straw, wood, and solar energy as auxiliary energy sources. In the plains areas, households mainly depend on coal and use grass, straw, solar energy, and wood as auxiliary energy sources. Energy used for cooking and heating, both of which are required for basic survival, accounted for most of the energy consumption. In the hilly, mountainous areas, households relied on kangs (an integrated system for cooking, sleeping, household heating, and ventilation) for heat in the winter. In the semi-mountainous areas, households used both kangs and stoves for heat. In the plains along the river district, households primarily depended on stoves for heat.

Conclusions: The characteristics of energy combination provide the evidence that farmers tend to make full use of their own resources to achieve maximum utility. Eco-environmental and economic problems should both be considered and consequently resolved together for optimal rural energy development.

Keywords: Rural household energy, Energy consumption, Village differences, Loess hilly region

\section{Background}

Energy is the most basic material demand for the existence and development of human being. Energy consumption is used as the criterion for measuring the level of economic and social development for a certain region [1]. Due to the energy crisis and other environmental, economic, political, market, and social issues, researchers have sought to develop sustainable

\footnotetext{
* Correspondence: jsdlgz@163.com

College of Tourism and Geographical Sciences, Jilin Normal University, Siping 136000, China
}

and renewable energy sources to reduce energy consumption, protect the environment, and promote regional development [2].

Household energy consumption accounts for a substantial proportion of the total energy consumption worldwide. In certain European and North American and South American countries, household energy use accounts for approximately $30 \%$ of total energy consumption [3, 4]. In China, the rapid development of the economy and society in past decades have resulted in an increasingly high energy demand, for which household 
energy consumption has accounted for a significant proportion [5-8]. It has been reported that residential energy consumption was approximately $11 \%$ of China's total energy consumption in 2012 [9].

In the vast rural areas of developing countries, there are extensive and profound connections which link regional economic and social development and environmental protection with the supply and demand of energy.

Because of the growing concern regarding rural household energy consumption, several research areas have emerged. The first area of research focuses on changes in the household energy consumption structure. Multiple factors, including local energy resources and economic, social, cultural, and natural geographical factors, influence the rural household energy consumption structure [10, 11]. Optimizing the energy structure and adjusting energy management policy are important aspects of promoting the improvement of rural areas in developing countries [12-14].

The second area of research focuses on the utilization and exploitation of renewable energy. The evaluation of the potential exploitation of fuel sources in different regions, particularly renewable energies such as solar energy, wind energy, biomass, and terrestrial heat, has shown great potential; however, energy utilization is restricted because households must pay for their energy usage. The shortage of energy sources continues to be a long-standing problem [15-17]. The improvement of resource use technology and the transformation of resource consumption patterns are not the only approaches available to resolve energy shortages; however, they play important roles in improving the efficiency of resource use and reducing environmental pollution. These approaches have been used in the rural areas of Asia and Africa with beneficial results [18-20].

Because rural areas hold a large population, household energy consumption in these areas is significant, and traditional methods of energy consumption used by thousands of households cause tremendous destruction to the environment of China. China comprises a vast territory: its natural conditions are complicated, economic development levels are widely different, and regional differences in rural household energy consumption are apparent. Solving the rural energy problem in China requires the combination of strategic planning by the national energy system and full awareness of regional differences in rural energy consumption; such a solution should be based on the energy requirements of actual regions and include effective, scientific planning, and design of rural energy development strategies [21].

Similar to other developing countries, China has a renewable energy program for citizens living in rural areas that are often very remote. Within the framework of this program, numerous renewable energy technologies have been developed in the past and are currently being developed to address rural energy shortages [22, 23]. The two most important renewable energy technologies used in the rural areas of China are bio-gas digesters and solar stoves. Bio-gas production is an important aspect of the energy strategy in China [24].

In the study area of Gansu Province in Northwest China, the rural energy construction program was initiated in the 1970s and thus has a relatively long history. In 2000, the national government strengthened the program, and Gansu's rural renewable energy construction program profited by this opportunity for development. At the end of 2011, 308,000 households owned rural bio-gas digesters, and 788,000 solar stoves were distributed in Gansu Province [25].

In the Loess hilly region, many residents are poverty stricken, the environment is fragile, household energy shortages exist, and excessive biomass consumption has become an important factor contributing to ecological degradation [26]. Due to the complexity of the terrain and villages that are located in different terrain areas, there are differences in the planting structure, the energy resource endowment structure, and economic development levels. Therefore, it is vital to research the differences in rural energy use between these different types of villages to strengthen pertinent rural energy policy implementation and correctly adjust the measures to local conditions.

Prior studies have analyzed issues such as greenhouse gas emissions, energy poverty, and health risk; however, insufficient attention has been paid to the differentiations in rural household energy consumption. On a micro-scale, this study examines the differences in rural household energy consumption for different types of villages in the Loess hilly region in Gansu Province. We obtained relevant data via questionnaire survey and analyzed the current situation in rural family life and the respective energy consumption structures and village differences. We then developed a model of rural energy construction for the different types of villages and provided a basis for policy design relating to regional development and environmental management.

\section{Methods}

\section{Description of study area}

The Loess hilly region in the center of Gansu Province includes broken terrains and ravines. It suffers from the most serious soil erosion within the Loess Plateau region; thus, its ecological environment is fragile. In this area, crisscrossing gullies and sparse vegetation on loose soil are mostly unprotected against heavy rain, which leads to severe erosion and delivers soil and water into the gullies. The most severe loss of water and soil is in the Loess Plateau where the annual average temperature 
is between 5.9 and $10.4{ }^{\circ} \mathrm{C}$. Precipitation is approximately $400 \mathrm{~mm}$, and loose soil is easily cultivated. There is a long agricultural history in the Loess Plateau, and archeological studies on the Dadiwan Ruins of Qin'an County have demonstrated that crop planting occurred in the region more than 7000 years ago [27]. When farmland is barren and dry and produces a low-yield cultivation, land becomes the primary method of increasing the food supply. When household energy is extremely scarce, farmers use local materials such as large amounts of crop straw, trees, and weeds for cooking and heating. This leads to a significant challenge in deciding whether to utilize these materials for fuel, feed, or fertilizer [28]. The demand for food leads to reclaiming steep-slope lands, and the demand for fuel damages vegetation. Due to an increase in population and less land for families to cultivate, a low level of agricultural production and subsequent farmer poverty are common in low-income areas in China. Such a high demand places great pressure on resources and the environment and seriously restricts sustainable development for this region. Household energy consumption is a process that involves key interaction between the environment and the economy, as demonstrated in Fig. 1.

Since 1999, the nation has implemented Western Development Strategies. The goal of the strategy is to return the region from farmland to forest and grassland in order to implement natural forest protection. The agriculture ministry has implemented the Ecology Household Project (EHP) in this region since 2003. The EHP was founded on the concept of renewable energy resources. The objective of EHP is to transform the agricultural production and lifestyle of traditional rural households through the application of technologies and engineering that are carefully matched to different types of households.

In addition, farmers' incomes have increased. Coal, electricity, and liquid gas consumption have also increased, which has prompted an upgrade to the local energy structure [29]. In poverty-stricken areas with fragile environments, solving basic energy requirements is of practical significance. This includes vegetation protection and expanding this protection incrementally [30]. Effectively utilizing existing biomass resources and improving energy use technology and energy efficiency are effective methods to solve certain local ecological and economic problems.

\section{Surveys}

To quantitatively compare the differences among household energy consumption for different villages, it is necessary to obtain reliable data and design an appropriate method.

For this survey, the study area was divided into three different terrains including mountainous areas, semimountainous areas, and plains areas. Hilly mountain villages were located in the mountains at high altitudes and experienced a significant temperature fluctuation between day and night. The agricultural planting structure was used more often than traditional agriculture. Production was not high, and there was extensive cultivation. These areas were affected by a drought climate which resulted in unstable agricultural production. Furthermore, these villages were located a great distance from town which made traffic inconvenient. Lastly, these villages had a low economic level. Semi-mountainous areas were typically located on the mountainside, with an altitude lower than that of the mountainous areas.

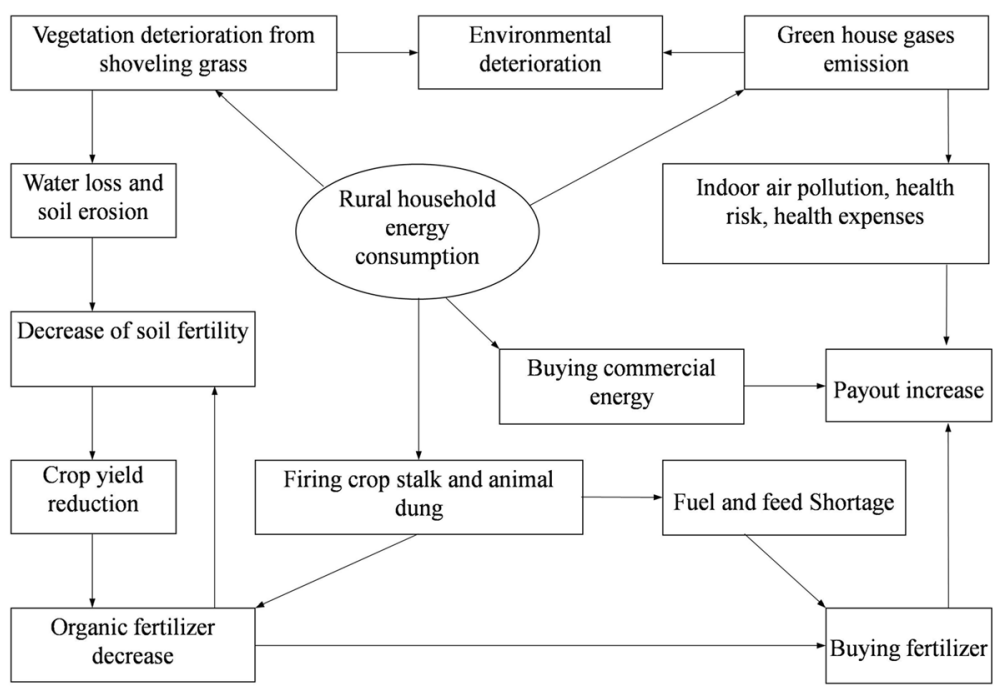

Fig. 1 Rural energy consumption's impact on the environment and the economy 
Agricultural planting structures were used more often than traditional agriculture, and farmers planted a small number of cash crops. Traffic was relatively inconvenient because the villages were of a great distance away from towns. Plains area villages had the best local economic conditions. The fluvial outwash land was fertile, and the areas had water security. The agriculture industry gave priority to economic crops and planted fruit and vegetables primarily for surrounding urban areas and other markets. In the plains areas, farmers were wealthier than those in the other two areas.

In June 2012, we conducted a pre-test survey to affirm the validity of the sample and reconstructed the wording of our questions to ensure the questionnaire (Additional file 1) was clear and user-friendly.

In July and December 2012, 13 representative villages in Qin'an and Tongwei Counties were surveyed. Tazipo, Qiyao, Jiahe, Pindao, Liangxian, Xiedao, Dougou, and Dunwan are mountainous hilly villages. The Heishitou, Qizui, and Dapin villages are located in semi-mountainous areas. Sizui and Houtan were located in the plains area (Fig. 2). The basic conditions of the 13 villages are provided in Table 1.

We visited 390 peasant families and effectively surveyed 371 farmers which accounted for $24.65 \%$ of the total number of households in the 13 villages. The families surveyed included both high-income households (annual household income above 40,000 yuan) and lowincome households (annual household income above
5000 yuan). Peasant families included three-generation families and nuclear families.

The survey data contained detailed geographic information at the village level and included the natural characteristics of each village surveyed because the geographic location significantly influenced household energy choices and consumption in rural areas. Collected data included the distance between villages, the distance to the nearest town, the latitude of the village, and the topographical features of the villages.

Detailed information was collected regarding household energy consumption, particularly the installation and use of bio-gas digesters and solar stoves. Each type of fuel that was used for 1-day cooking and heating was evaluated. The thermal efficiencies of bio-gas and solar heating of water were measured. In the survey, we gathered information regarding household characteristics including family labor, basic demographic and educational information for all household members, housing conditions, and family assets. The data from the survey also contained information regarding household production activities, such as livestock production, land ownership, and off-farm employment. During the survey process, we discussed the representation of sample data with officials from rural energy management offices from both Qin'an and Tongwei Counties.

\section{Calculation method}

Statistical data collected from the field investigations were used to calculate annual household energy consumption.

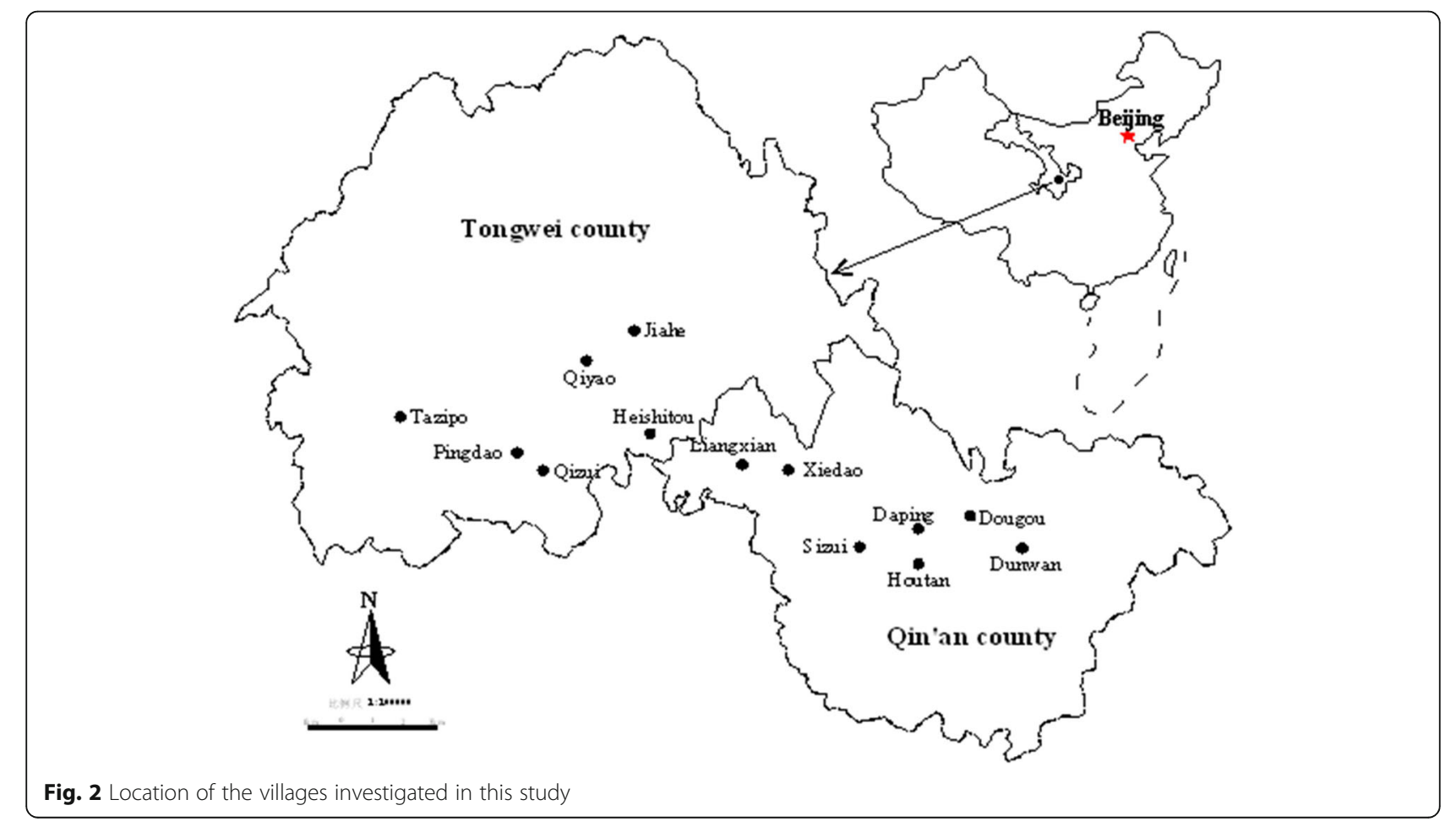


Table 1 Basic conditions of the three types of villages

\begin{tabular}{|c|c|c|c|c|c|}
\hline Location & $\begin{array}{l}\text { Altitude } \\
(\mathrm{m})\end{array}$ & $\begin{array}{l}\text { Number in } \\
\text { household }\end{array}$ & $\begin{array}{l}\text { Number of households } \\
\text { investigated }\end{array}$ & $\begin{array}{l}\text { Per door } \\
\text { farmland (ha) }\end{array}$ & $\begin{array}{l}\text { Average yearly household } \\
\text { income (yuan) }\end{array}$ \\
\hline \multicolumn{6}{|c|}{ Mountainous areas } \\
\hline Tazipo & 1902 & 54 & 21 & 2.045 & 7005 \\
\hline Qiyao & 1752 & 112 & 29 & 1.784 & 7170 \\
\hline Jiahe & 1875 & 67 & 22 & 1.677 & 9030 \\
\hline Pindao & 1715 & 110 & 21 & 0.955 & 7680 \\
\hline Liangxian & 1858 & 97 & 25 & 1.034 & 9270 \\
\hline Xiedao & 1834 & 44 & 16 & 0.757 & 5820 \\
\hline Dougou & 1726 & 215 & 30 & 0.465 & 8025 \\
\hline Dunwan & 1778 & 44 & 20 & 0.803 & 9915 \\
\hline \multicolumn{6}{|c|}{ Semi-mountainous areas } \\
\hline Heishitou & 1633 & 125 & 37 & 1.255 & 10635 \\
\hline Qizui & 1583 & 103 & 35 & 0.888 & 10035 \\
\hline Dapin & 1530 & 103 & 33 & 0.453 & 6030 \\
\hline \multicolumn{6}{|l|}{ Plains areas } \\
\hline Sizui & 1347 & 326 & 54 & 0.049 & 11985 \\
\hline Houtan & 1257 & 105 & 28 & 0.183 & 15900 \\
\hline Total & - & 1505 & 371 & - & - \\
\hline
\end{tabular}

The total energy consumption of households can be calculated using the following formula:

$$
\mathrm{Te}=\sum_{j=1}^{m} \sum_{i=1}^{n} x_{i j}(i=1,2 \ldots n, j=1,2 \ldots m)
$$

where

Te-total energy of household consumption

$n$-types of energy resources

$m$-types of energy consumption

$x_{i j}$-the amount of the $i$ th type of resource to use for the $j$ th type of purpose

Energy resources were converted into standard coal equivalents to compare with different energy structures. The conversion factors from physical units to coal equivalents [31] are provided in Table 2.

\section{Results and discussion}

\section{Village differences in household energy consumption}

(1)Overall structure of household energy consumption

Presently, rural household energy use primarily includes cooking and heating (using either a stove or a kang bed stove). Heating water, slow-boiling tea, lighting, and electrical home appliances (e.g., televisions, music equipment, video recorders, washing machines) all consume small amounts of energy. Existing energy sources include crop straw, coal, grass, wood, animal dung, electricity, solar energy, and LPG (liquefied petroleum gas). According to the questionnaire data on the corresponding consumption of all types of energy and energy consumption projects, we figured out the household energy consumption structure for the three types of villages (Table 3). The household energy totals, for mountainous areas, semi-mountainous areas, and plains areas, 2030.52, 1921.54, and 2166.48 KgCE, respectively.

(2)Village differences in energy portfolio characteristics

According to the survey data, rural household energy consumption indicated distinct energy portfolio characteristics. The mountainous area households used straw, coal, dung, solar energy, and wood mainly and used bio-gas as only an auxiliary energy source. The semi-mountainous area households used coal, grass, straw, and solar mainly and used wood as only an auxiliary energy source. The plains areas used coal, grass, and straw mainly and used solar energy as only an auxiliary energy source (Fig. 3).

Table 2 The conversion coefficient for energy resources

\begin{tabular}{cccccccccc}
\hline & Crop residues $(\mathrm{kg})$ & Grass $(\mathrm{kg})$ & Firewood $(\mathrm{kg})$ & Dung $(\mathrm{kg})$ & Coal $(\mathrm{kg})$ & Electricity $(\mathrm{kWh})$ & Bio-gas $\left(\mathrm{m}^{3}\right)$ & Solar $(\mathrm{MJ})$ & LPG $(\mathrm{kg})$ \\
\hline Conversion coefficient & 0.500 & 0.428 & 0.571 & 0.500 & 0.714 & 0.123 & 0.714 & 0.034 & 1.714 \\
\hline
\end{tabular}


Table 3 Structure of rural household energy consumption for the three types of villages (KgCE)

\begin{tabular}{|c|c|c|c|c|c|c|c|c|c|c|}
\hline & Crop straw & Grass & Wood & Animal dung & Coal & Electricity & Bio-gas & Solar energy & LPG & Total \\
\hline \multicolumn{11}{|l|}{ Mountainous village } \\
\hline Cooking & 452.45 & 0.00 & 16.64 & 0.00 & 245.08 & 2.24 & 41.43 & 75.03 & 0.81 & 833.68 \\
\hline Boiling tea & 0.00 & 0.00 & 10.18 & 0.00 & 0.00 & 0.55 & 0.00 & 0.00 & 0.00 & 10.73 \\
\hline Lighting & 0.00 & 0.00 & 0.00 & 0.00 & 0.00 & 4.98 & 0.00 & 0.00 & 0.00 & 4.98 \\
\hline Heating kang & 380.73 & 240.4 & 0.00 & 125.77 & 31 & 0.97 & 0.00 & 0.00 & 0.00 & 778.87 \\
\hline Stove & 0.00 & 0.00 & 15.17 & 0.00 & 379.15 & 0.00 & 0.00 & 0.00 & 0.00 & 394.32 \\
\hline Home appliance & 0.00 & 0.00 & 0.00 & 0.00 & 0.00 & 7.94 & 0.00 & 0.00 & 0.00 & 7.94 \\
\hline Total & 833.18 & 240.4 & 41.99 & 125.77 & 655.23 & 16.68 & 41.43 & 75.03 & 0.81 & 2030.52 \\
\hline \multicolumn{11}{|c|}{ Semi-mountainous village } \\
\hline Cooking & 184.21 & 75.43 & 44.64 & 0.00 & 457.79 & 1.37 & 0.00 & 97.22 & 0.00 & 860.66 \\
\hline Boiling tea & 0.00 & 0.00 & 5.02 & 0.00 & 0.00 & 2.04 & 0.00 & 0.00 & 0.00 & 7.06 \\
\hline Lighting & 0.00 & 0.00 & 0.00 & 0.00 & 0.00 & 7.21 & 0.00 & 0.00 & 0.00 & 7.21 \\
\hline Heating kang & 154.48 & 311.15 & 0.00 & 0.00 & 57.72 & 0.00 & 0.00 & 0.00 & 0.00 & 523.35 \\
\hline Stove & 0.00 & 0.00 & 19.65 & 0.00 & 491.9 & 0.00 & 0.00 & 0.00 & 0.00 & 511.55 \\
\hline Home appliance & 0.00 & 0.00 & 0.00 & 0.00 & 0.00 & 11.71 & 0.00 & 0.00 & 0.00 & 11.71 \\
\hline Total & 338.69 & 386.58 & 69.31 & 0.00 & 1007.41 & 22.33 & 0.00 & 97.22 & 0.00 & 1921.54 \\
\hline \multicolumn{11}{|l|}{ Plains village } \\
\hline Cooking & 64.85 & 87.34 & 35.94 & 0.00 & 583.26 & 1.48 & 0.00 & 114.78 & 5.45 & 893.1 \\
\hline Boiling tea & 0.00 & 0.00 & 0.00 & 0.00 & 0.00 & 4.24 & 0.00 & 0.00 & 0.00 & 4.24 \\
\hline Lighting & 0.00 & 0.00 & 0.00 & 0.00 & 0.00 & 9.31 & 0.00 & 0.00 & 0.00 & 9.31 \\
\hline Heating kang & 97.63 & 352.28 & 0.00 & 0.00 & 95.95 & 0.15 & 0.00 & 0.00 & 0.00 & 546.01 \\
\hline Stove & 0.00 & 0.00 & 26.98 & 0.00 & 675.39 & 0.00 & 0.00 & 0.00 & 0.00 & 702.37 \\
\hline Home appliance & 0.00 & 0.00 & 0.00 & 0.00 & 0.00 & 11.45 & 0.00 & 0.00 & 0.00 & 11.45 \\
\hline Total & 162.48 & 439.62 & 62.92 & 0.00 & 1354.6 & 26.63 & 0.00 & 114.78 & 5.45 & 2166.48 \\
\hline
\end{tabular}

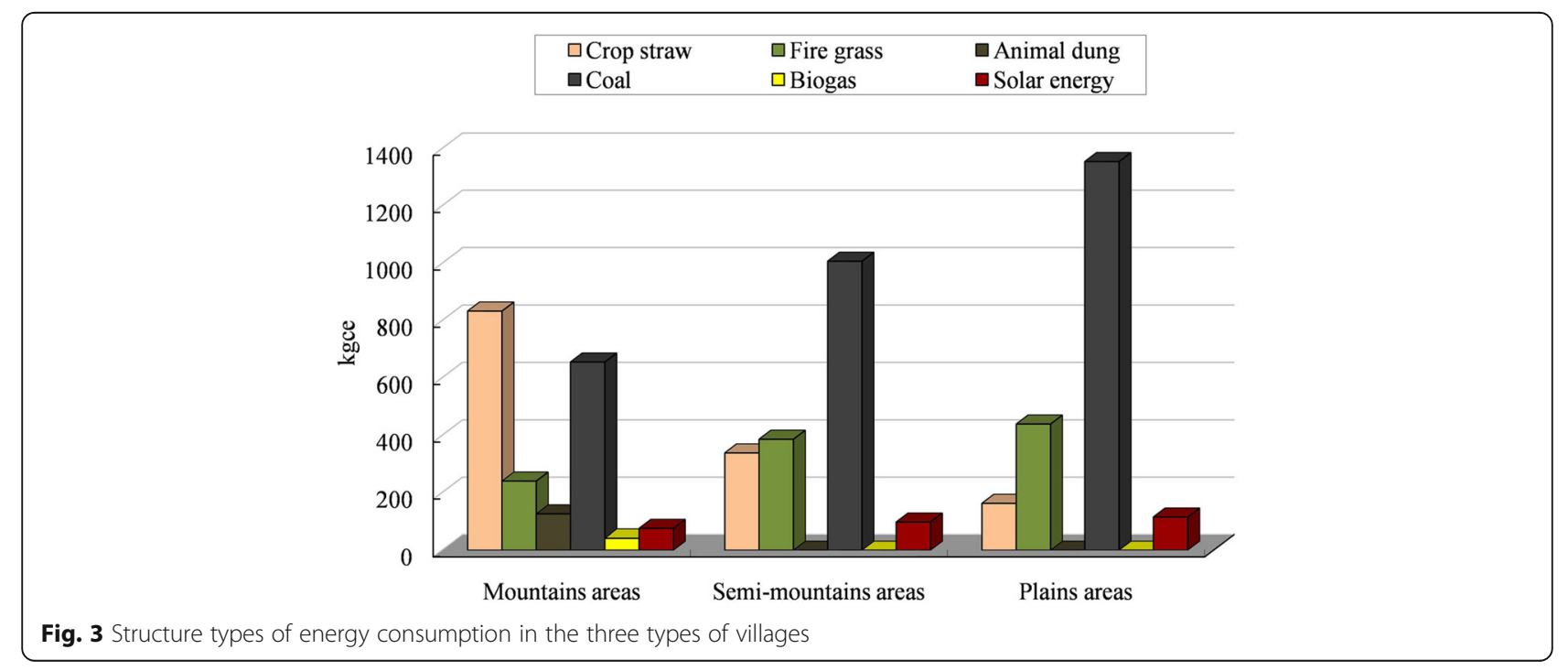


The data in Table 3 indicate that the mountainous area households consumed the greatest amount of straw of approximately $833.18 \mathrm{KgCE}$, and the plains area households consumed the least amount of straw of only 162.48 KgCE. Semi-mountainous area households consumed approximately $338.69 \mathrm{KgCE}$ of straw. A peasant household consumes straw generally to provide selfsustaining energy, and the gain depends on the farmers' planting structures and production. Large amounts of farmland are available for each farmer, and the farmers in hilly mountainous areas grow traditional agricultural crops to obtain more straw. In the plains areas, farmers plant fruit trees, vegetables, and other economic crops. Only a few farmers grow traditional crops, and fewer farmers grew straw.

The coal consumption per household in the plains areas was $354.6 \mathrm{KgCE}$, and in the semi-mountainous areas, consumption was 1007.41 KgCE. In the mountainous areas, consumption was less than half of that in plains areas, which was 655.23 KgCE. Commercial energy consumption is affected by the farmers' economic situation and the amount of self-produced energy. Plains areas farmers use less noncommercial energy, and most farmers bought coal as a supplement. In addition, we determined that many poor farmers in the plains areas continue to use grass as their primary energy resource. Coal use was seldom reported during the survey.

The plains area households consumed the grass most, followed by the semi-mountainous areas and mountainous areas. In our survey, the three types of areas consume the grass $439.62,386.58$, and $240.40 \mathrm{KgCE}$, respectively. The kang was the most basic heating method for mountainous areas during the winter. Fuels consumed included straw, grass, dung, and coal dust. Farmers harvested a small amount of stalks in the plains areas and in general did not raise large animals that would produce manure for fuel; therefore, grass was commonly used to heat kangs.

Electricity was widely used clean energy in the Loess hilly region in Gansu, but clean energy consumption was rare overall. The plains area consumed electricity most at $26.63 \mathrm{KgCE}$; the semi-mountainous areas consumed 22.33 KgCE and the mountainous area households consumed electricity the least at only16.68 KgCE (see Table 3).

According to the surveys, when consuming energy, farmers select the type of energy based on cost, availability, convenience, and cleanliness. Energy cost was the primary factor considered when consumers selected which fuel to use because their choices were limited by their ability to pay. Ordered from the highest to the lowest, the types of household energy used were the following: straw and grass, household bio-gas, coal, electricity, and liquefied gas. Three other factors (availability, convenience, and cleanliness) were also considered when the farmers chose fuels. Real household energy consumption patterns were determined by the farmers' selection of energy sources under existing conditions. There continued to be an energy shortfall after peasants consumed all of the biomass fuel; therefore, solar stoves, coal, and LPG were needed to meet their basic energy needs. The characteristics of combined energy sources provided evidence that farmers used their own resources to realize utility maximization.

\section{(3) Village differences in energy consumption structure}

Regarding household energy, heating and cooking consumed the most energy in the Loess hilly region in Gansu. In the mountainous, semi-mountainous, and plains areas, heating and cooking accounted for 98.98, 99.11 and $98.94 \%$ of the total life-sustaining energy consumption, respectively (Fig. 4).

Kangs and stoves were the primary heating methods in the rural areas and consumed the most energy. In the mountainous areas, the heating energy consumption per household was $1173.19 \mathrm{KgCE}$ in the winter, which was approximately three fifths of all consumed energy, and heating kang was primarily used as heating energy consumption. In the semi-mountainous areas, the heating energy consumption per household was $1034.9 \mathrm{KgCE}$. The kang and stove were equally used for heating, and each accounted for approximately half of the usage. The per household heating energy consumption was $1248.38 \mathrm{KgCE}$ in the plains areas. The stove was primarily used for heating and accounted for $60 \%$ of overall usage. Overall, heating energy used more fuel in the plains areas, and the stove was the primary heating method; coal consumption produces more effective heat energy and the heating effect is superior.

The consumption of cooking energy in peasant households in mountainous, semi-mountainous, and plains areas were $833.68,860.66$, and $893.1 \mathrm{KgCE}$, respectively. In the mountainous areas, straw was used primarily and coal was a secondary used energy source. In semimountainous areas, coal was primarily used and straw was a secondary used energy source. Coal comprises up to $65 \%$ of the cooking energy in the plains areas.

For lighting and electrical appliances, the usage proportion was less than $1 \%$.

Residents of villages drank canned tea in the Loess hilly region, which consumed little energy. Data indicated that the hilly areas used firewood for preparing tea, the plains areas used electricity, and the semi-mountainous areas used firewood and electricity equally.

Household energy use structures, in some degree, reflected the local residents' living standards. Overall, in the Loess hilly region in Gansu, cooking and heating, which were the basic survival needs, were the main energy usage. Entertainment, television, audio, 


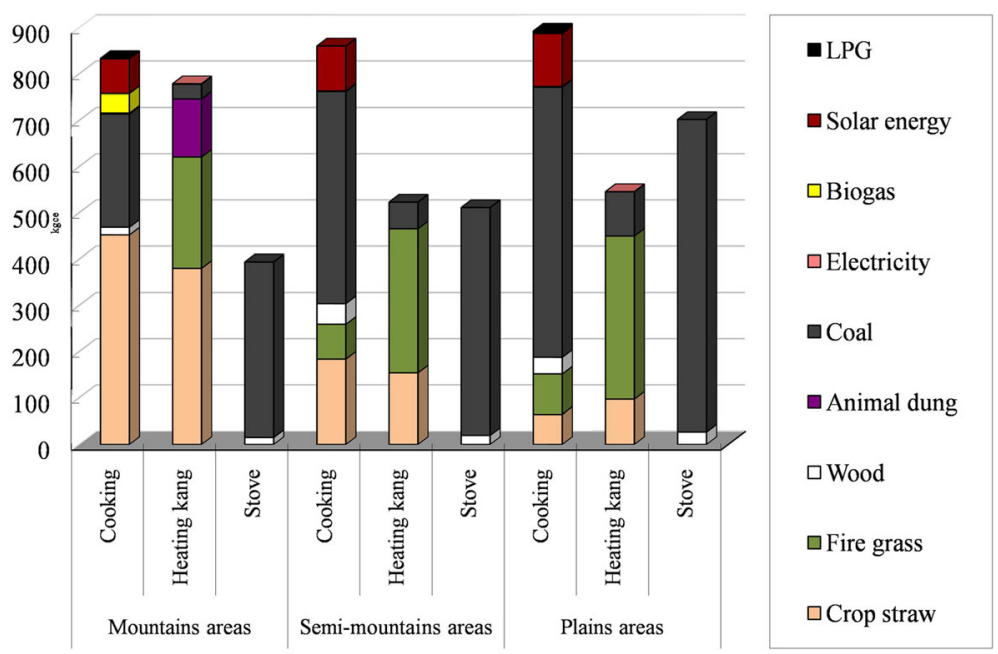

Fig. 4 Energy consumption in the three types of villages

and other household appliances occupied only a small proportion of energy consumption.

\section{Discussion of rural household energy construction}

Rural energy construction must take advantage of local resources. In the Loess region of the Gansu Province, where rural households are impoverished and water loss and soil erosion are serious matters, the issue of household energy shortages must be solved to improve the environment. Bio-gas digesters, energy-saving kangs, and solar stoves should be more widely utilized.

This study revealed that a beneficial cycle has been established within the ecosystem that closely linked biogas production, crop cultivation, and household animal husbandry due to the effective use of nutrient materials, biological energy, and solar energy in this region (Fig. 5). Household heating played an important role in many

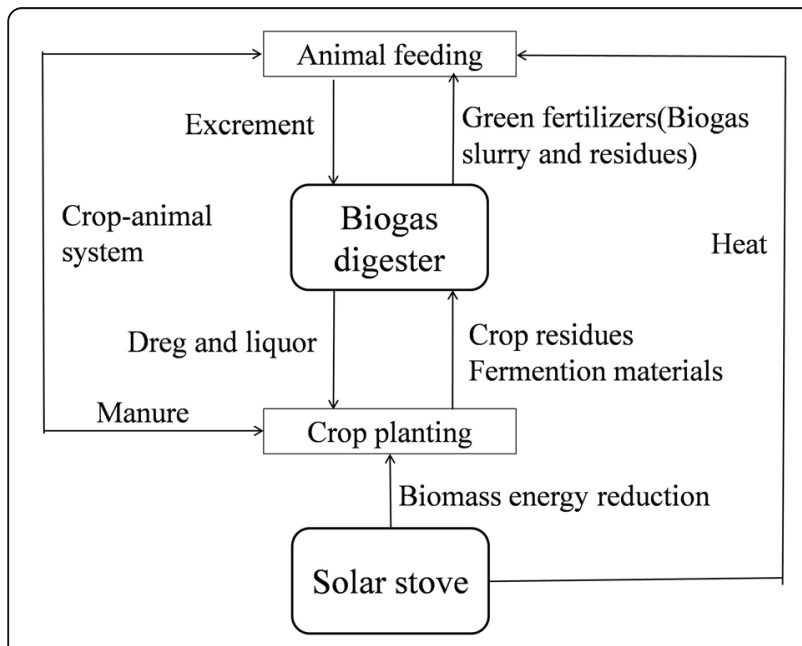

Fig. 5 Energy flow in the rural energy consumption system aspects of energy demand. For a long period of time, Chinese kangs and stoves have been used in rural areas for household heating purposes. These two appliances provide heat for rural residents during extremely cold weather; however, indoor thermal comfort remains poor throughout winter. Innovating traditional kangs and building energy-saving kangs are primary methods to enhance quality-of-life and to protect the environment, both of which have important strategic significance for sustainable energy use in rural areas.

People in mountainous areas and semi-mountainous areas are subject to shortages of water, fuel, and fertilizer, which hinder local economic development. Rural energy construction should be based on terracing and rainwater collection. The primary energy construction components include bio-gas digesters, solar cookers, energy-saving kangs, sunlight greenhouses, and water cellars. A water cellar is a type of rainwater collection technology invented by farmers in Gansu Province in China for survival in a harsh, dry environment where rainfall only occurs in July, August, and September. A water cellar is used to store rainwater runoff within a cemented cellar during the wet season for residents and livestock to use during the dry season. A water cellar may store $30-40 \mathrm{~m}^{3}$ of water and can sustain a family of five for up to 5 months.

For villages in the plains with superior economic conditions, the primary energy production was vegetable and fruit cultivation. Bio-gas acted as a link, driving livestock husbandry, reducing overall agricultural production costs, and producing pollution-free vegetables, thus improving farmers' incomes and promoting rural economic development. The primary energy construction elements included greenhouses, bio-gas digesters, energy-saving kangs, and solar cookers. 
By improving economic conditions for families, enhancing resource availability, and changing consumption practices, we can constantly upgrade rural energy consumption structures and gradually diversify it from a single traditional energy consumption structure toward high-quality energy consumption. This transition allows us to take effective measures to promote and guide this shift, which is of great significance for ecological protection and improving consumption structures.

\section{Conclusions}

In this study, we analyzed current rural household energy consumption structures. This study differs from prior studies because we focused on differences among different types of villages, using data collected by questionnaires from371 rural households in the Loess hilly region of Gansu Province, China. According to the study, the household energy totals for mountainous, semi-mountainous, and plains areas were 2030.52, 1921.54, and 2166.48 KgCE, respectively. Total energy consumption was less in rural areas. The energy sources that peasants obtained only met their basic living demands and were insufficient to improve their living standards.

This article revealed differences in energy portfolio characteristics among different village regions. The mountainous areas used straw, coal, dung, solar energy, and wood mainly and used bio-gas as only an auxiliary energy source. The semi-mountainous areas used coal, grass, straw, and solar mainly and used wood as only an auxiliary energy source. The plains areas used coal, grass, and straw mainly and used solar energy as an auxiliary energy source. People in mountainous areas depend on straw the most; those in the plains areas depend on straw the least. People in the mountainous areas used kang primarily for heating in the winter, those in the semi-mountainous areas used both kang and stove for heating, and those in the plains areas primarily used the stove for heating. The characteristics of the energy combinations provide evidence that farmers make full use of their various resources to realize utility maximization.

Economic conditions, resource availability, and consumption are the primary influencing factors that determine rural energy consumption levels and structure changes. The improvement of farmers' economic conditions results in a limited ability to purchase energy and played a positive role in reducing biomass energy consumption. Currently, the energy structure is undergoing a historic transformation period.

Rural energy construction must take advantage of local resources and combine demand with their potential to match rural, economic, and social development. It is important to consider energy conservation, emissions reduction, and ecological protection; however, we must also consider the actual capacity of the farmers. Applications of new technologies and appliances are technically feasible and have an economic rationale.

This study contributes to the current knowledge regarding household energy consumption on the microscale, the development of more effective intervention strategies, long-term energy conservation, and sustainable development. The limitation of this study lies on two aspects. Firstly, this paper researches into the village differences of rural household energy consumption taking the Loess hilly region of China as an example; however, further study on the internal mechanism is still needed. Secondly, the topographic condition affects the agricultural activities and the income structure and has influences on the household energy consumption. So, future studies may expand the sample size and improve the method of analysis, discussing deeply the optimal rural energy development of different topographic conditions.

\section{Additional file}

Additional file 1: Questionnaire of rural household energy

consumption. (DOCX $26 \mathrm{~kb}$ )

Abbreviations

EHP: Ecology Household Project; KgCE: Kilogram of coal equivalent

Acknowledgements

The authors would like to thank the anonymous reviewers for their constructive comments and suggestions. This research was supported by the National Social Science Fund of China (No. B13CSH068) and the Humanities and Social Science Research Project of Chinese Ministry of Education (No. 10YJCZH070).

\section{Authors' contributions}

GL designed the study, conducted the survey, and drafted the article. JS and AD proof read and edited the article and designed the figures. All authors read and approved the final manuscript.

\section{Competing interests}

The authors declare that they have no competing interests.

Received: 23 February 2016 Accepted: 28 October 2016

Published online: 21 November 2016

\section{References}

1. Sayin C, Mencet M, Ozkan B (2005) Assessing of energy policies based on Turkish agriculture: current status and some implications. Energy Policy 33:2361-2373

2. Abbas M, Ahmad J, Edmundas K, Fausto C, Zainab K (2015) Sustainable and renewable energy: an overview of the application of multiple criteria decision making techniques and approaches. Sustainability 7:13947-13984

3. ElA (2009) Annual energy review 2009. US Energy Information Administration, Washington

4. EEA (2008) Energy and environment report. Copenhagen: European Environment Agency (EEA), EEA Report No 6/2008

5. Ouyang J, Hokao K (2009) Energy-saving potential by improving occupants' behavior in urban residential sector in Hangzhou City, China. Energy Build $41: 711-720$

6. Wang Z, Zhang B, Yin J, Zhang Y (2011) Determinants and policy implications for household electricity-saving behaviour: evidence from Beijing, China. Energy Policy 39:3550-3557 
7. Song M, Song Y, An Q, Yu H (2013) Review of environmental efficiency and its influencing factors in China: 1998-2009. Renew Sustain Energy Rev 20:8-14

8. Zhou K, Yang S, Shen C, Ding S, Sun C (2015) Energy conservation and emission reduction of China's electric power industry. Renew Sustain Energy Rev 45:10-19

9. National Bureau of Statistics of China (NBSC) (2014) China energy statistical year-book. China Statistics Press, Beijing

10. Zhai F (2003) China's rural energy development policy adjustment problem study. J Nat Resour 18:81-86

11. Wang X, Feng Z, Jiang K (1999) On household energy consumption for rural development: a study on Yangzhong County of China. Energy 24:493-500

12. Catania P (1999) Chinese rural energy system and management. Appl Energy 64:229-240

13. Ghiorgis W (2002) Renewable energy for rural development in Ethiopia: the case for new energy policies and institutional reform. Energy Policy 30:1095-1105

14. Zhong Y, Cai W, Wu G, Ren H (2009) Incentive mechanism design for the residential building energy efficiency improvement of heating zones in North China. Energy Policy 37:2119-2123

15. Yan L, Min Q, Cheng S (2005) Energy consumption and bio-energy development in rural areas of China. Resour Sci 27:8-13

16. Taele B, Gopinathana K, Mokhuts'oane L (2007) The potential of renewable energy technologies for rural development in Lesotho. Renew Energy 32:609-622

17. Frederick N, Reccab O, Ochieng M (2006) The potential of solar chimney for application in rural areas of developing countries. Fuel 85:2561-2566

18. Sateikis I, Lynikiene S, Kavolelis B (2006) Analysis of feasibility on heating single family houses in rural areas by using sun and wind energy. Energy Buildings 38:695-700

19. Madubansi M, Shackleton C (2006) Changing energy profiles and consumption patterns following electrification in five rural villages, South Africa. Energy Policy 34:4081-4092

20. Guo X, Niu S, Li G, Wang H (2006) Estimate on the eco-economic benefits of rural energy sources construction and de-farming and reforestation. China Popul Resour Environ 16:98-102

21. Li G, Nie H, Yang Y (2010) The regional differences and influencing factors of China's rural life energy consumption. J Finance Econ Shanxi Univ 32:68-73

22. Valmiki M, Li P, Heyer J, Morgan M, Albinali A, Alhamidi K (2011) A novel application of a Fresnel lens for a solar stove and solar heating. Renew Energy 36:1614-1620

23. Chen L, Zhao L, Ren C, Wang F (2012) The progress and prospects of rural biogas production in China. Energy Policy 51:58-63

24. Nandwani S (1996) Solar cookers cheap technology with high ecological benefits. Ecol Econ 17:73-81

25. Niu H, He Y, Umberto D, Zhang P, Qin H, Wang S (2014) Rural household energy consumption and its implications for eco-environments in NW China: a case study. Renew Energy 65:137-145

26. Li G, Niu S (2008) Economic cost analysis of rural life energy consumption environment in the loess hilly region. J Nat Resour 23:15-24

27. Mo D, Li F, Li S, Kong Z (1996) A preliminary study on the pale environment of the middle Holocene in the Hulu River area in Gansu Province and its effects on human activity. Acta Geograph Sin 51:59-67

28. Li G, Dong D (2010) Environmental economic benefit analysis of rural household biogas construction in Wei River upstream of the loess hilly region. Renew Energy 28:115-123

29. Niu S, Zhang X, Zhao C, Niu Y (2012) Variations in energy consumption and survival status between rural and urban households: a case study of the Western Loess Plateau, China. Energy Policy 49:515-527

30 Qu W, Tu Q (2013) Which factors are effective for farmers' biogas use?-Evidence from a large-scale survey in China. Energy Policy 63:26-33

31 National Bureau of Statistics (2013) China Energy Statistical Yearbook 2012. China Statistics Press, Beijing.

\section{Submit your manuscript to a SpringerOpen ${ }^{\circ}$ journal and benefit from:}

- Convenient online submission

- Rigorous peer review

- Immediate publication on acceptance

- Open access: articles freely available online

- High visibility within the field

Retaining the copyright to your article

Submit your next manuscript at $\gg$ springeropen.com 